\title{
PENGARUH PERSONAL SELLING TERHADAP PENCAPAIAN TARGET PENJUALAN (STUDI KASUS PT. TELKOM INDONESIA (PERSERO) TBK
}

\author{
Mahyani, Sari Wulandari \\ Universitas Muslim Nusantara (UMN) Al-Washliyah Medan, Indonesia \\ Email: mahyani99@yahoo.com, sariwulandari@umnaw.ac.id
}

\begin{abstract}
Abstrak
Promosi adalah berbagai kegiatan yang dilakukan oleh perusahaan yang menonjolkan keistimewaan-keistimewaan produknya yang membujuk konsumen sasaran agar membelinya". Perusahaan harus memiliki target penjualan yang ingin dicapai agar perusahaan tersebut tetap mampu bersaing, dan tetap mampu berdiri membesarkan nama perusahaan tersebut, hal ini lah yang membuat banyak perusahaan mulai mengalami kesulitan saat target penjualan yang mereka ingin capai namun tidak mampu untuk mencapai. Penelitian ini dilakukan untuk mengetahui apakah terdapat pengaruh antara personal selling terhadap pencapaian target penjualan (studi kasus PT. Telkom Indonesia (persero) tbk. Unit bisnis Simpang Limun Medan). Metode yang digunakan dalam penelitian ini adalah bersifat kuantitatif dan sampel dalam penelitian ini berjumlah 50. Metode Penelitian yang digunakan dalam penelitian ini adalah metode Observasi, dokumentasi dan kuesioner dengan menggunakan skala likert. Teknik Analisis Data yang digunakan adalah regresi linier sederhana mengunakan SPSS. Berdasarkan hasil penelitian dapat diketahui bahwa Personal Selling (X) memiliki nilai t hitung sebesar 7,764, dan t table sebesar 0,361. Hal ini jika dibandingkan dengan t hitung maka hasilnya 7,764>0,361, sehingga dapat disimpulkan bahwa personal selling berpengaruh positif dan signifikat terhadap pencapaian target penjualan (Y). Hasil koefisien determinasi menunjukkan bahwa personal selling memberikan pengaruh terhadap pencapaian target penjualan sebesar 0,557 atau 55,7\% sedangkan sisanya sebesar $44,3 \%$ dipengaruhi oleh variabel lain yang tidak diteliti dalam penelitian ini.
\end{abstract}

Kata Kunci: personal selling; pencapaian target penjualan;

\section{Abstract}

Promotion is a variety of activities carried out by companies that highlight the features of their products that persuade target consumers to buy them. Companies must have sales targets that they want to achieve so that the company is still able to compete, and still be able to stand up and raise the name of the company, this is what makes many companies start to experience difficulties when the sales targets they want to achieve but are unable to achieve. to find out whether there is an influence between personal selling on the achievement of sales targets (case study of PT. Telkom Indonesia (Persero) tbk. Simpang Limun Medan business unit). The method used in this study is quantitative and the sample in this study amounted to 50. The research method used in this study was the method of observation,

$\begin{array}{ll}\text { How to cite: } & \text { Mahyani, M., \& Wulandari, S. (2021) Pengaruh Personal Selling terhadap Pencapaian Target } \\ & \begin{array}{l}\text { Penjualan (Studi Kasus PT. Telkom Indonesia (Persero) Tbk, Syntax Idea, } 3 \text { (8), } \\ \text { https://doi.org/10.36418/syntax-idea.v6i8.1411 }\end{array} \\ \text { E-ISSN: } & \text { 2684-883X } \\ \text { Published by: } & \text { Ridwan Institute }\end{array}$


documentation and questionnaires using a Likert scale. The data analysis technique used is simple linear regression using SPSS. Based on the results of the study, it can be seen that Personal Selling (X) has a t-count value of 7.764, and a t-table of 0.361 . This is when compared with $t$ arithmetic, the result is $7.764>0.361$, so it can be concluded that personal selling has a positive and significant effect on the achievement of sales targets $(Y)$. The results of the coefficient of determination indicate that personal selling has an influence on the achievement of sales targets of 0.557 or $55.7 \%$ while the remaining $44.3 \%$ is influenced by other variables not examined in this study.

Keywords: personal selling; achievement of sales targets;

\section{Pendahuluan}

Perusahaan akan berupaya untuk memperkenalkan Produk mereka kemasyarakat dengan melakukan promosi yang tepat hal ini mempengaruhi keputusan pembelian masyarakat terhadap produk yang ditawarkan dan pada akhinya bertujuan meningkatkan laba perusahaan, Menurut (Devika, 2015) promosi pada hakekatnya adalah suatu komunikasi pemasaran, artinya aktifitas pemasaran yang berusaha menyebarkan informasi, mempengaruhi/ membujuk, dan atau mengingatkan pasar sasaran atas perusahaan dan produknya agar bersedia menerima, membeli dan loyal pada produk yang ditawarkan perusahaan yang bersangkutan. Strategi pengembangan harus dibangun atas dasar adanya kesinambungan antara diferensiasi produk, saluran distribusi atau tempat yang strategis untuk melayani konsumen, proses dan bukti fisik yang saling mendukung.

Promosi adalah berbagai kegiatan yang dilakukan oleh perusahaan yang menonjolkan keistimewaan-keistimewaan produknya yang membujuk konsumen sasaran agar membelinya". Dan diharapkan akan berpengaruh terhadap keputusan pembelian nasabah sehingga mempengaruhi pencapaian target dan Outstanding load suatu perusahaan.

Perusahaan harus memiliki target penjualan yang ingin dicapai agar perusahaan tersebut tetap mampu bersaing, dan tetap mampu berdiri membesarkan nama perusahaan tersebut, hal ini lah yang membuat banyak perusahaan mulai mengalami kesulitan saat target penjualan yang mereka ingin capai namun tidak mampu untuk mencapai.

Hal ini Barang Atau Jasa yang di Produksi oleh perusahaan tesebut harus mampu memberikan keuntungan bagi perusahaan tersebut, dan yang lebih terpenting barang dan jasa yang dihasilkan perusahaan tersebut harus mampu dikenal oleh Konsumen dan harus mampu membuat konsumen mengunakan barang dan jasa yang dihasilkan perusahaan tersebut, hal ini disebabkan agar minat beli konsumen meningkat sehingga tercapai target dari penjualan perusahaan tersebut.

Tidak terkecuali untuk perusahaan Telekomunikasi dan Informasi seperti PT. Telkom Indonesia (Persero) Tbk, Perkembangan teknologi informasi yang pada awalnya melalui media surat menyurat, berkembang melalui media telepon koin 
ataupun telepon rumah, dan menggunakan telepon bergerak tanpa kabel yang lebih dikenal dengan handphone. Sejalan dengan perkembangan informasi dan komunikasi, saat ini pemenuhan kebutuhan tersebut dapat diperoleh melalui media yang lebih modern yaitu dengan memanfaatkan perkembangan teknologi internet. Berikut ini merupakan grafik penjualan produk IndiHome unit bisinis simpang limun Medan Januari 2021 - Juni 2021.

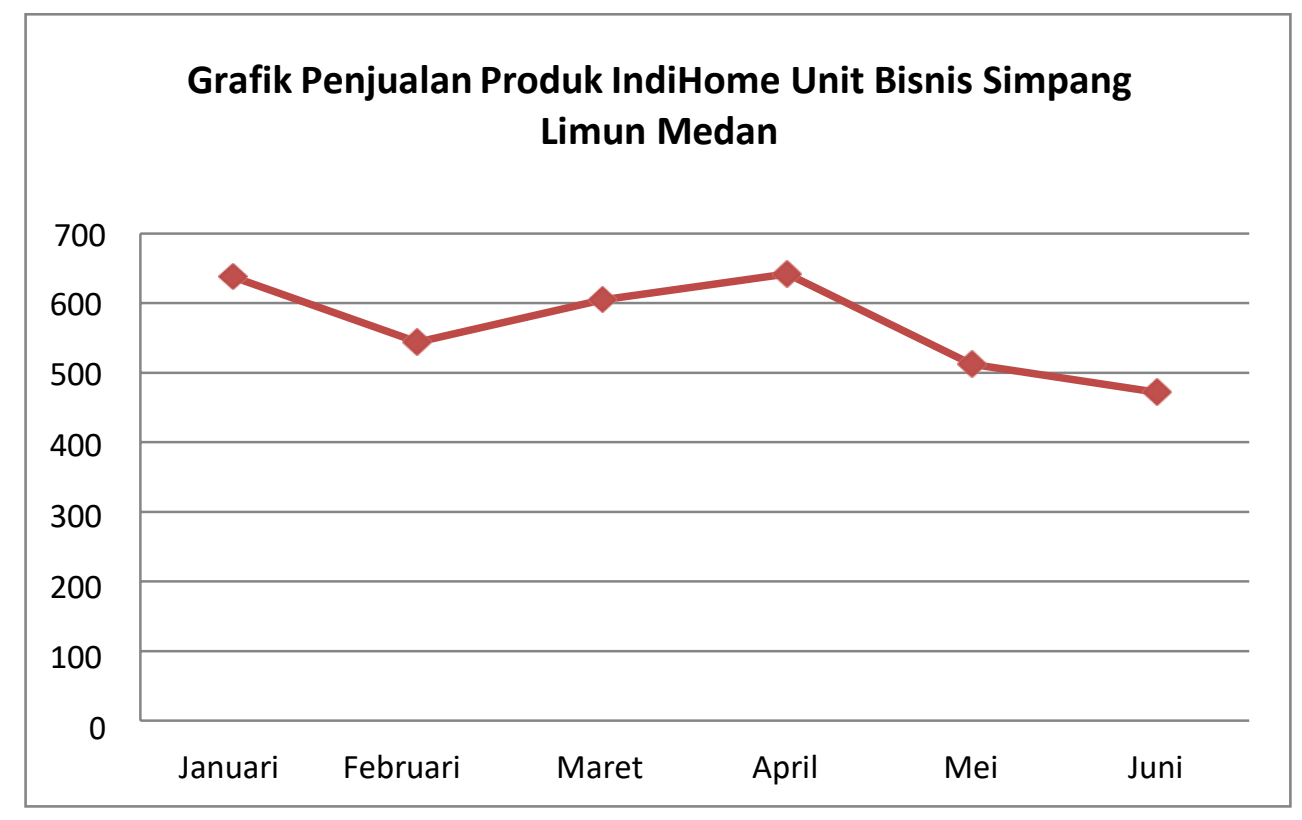

Dari grafik dan Penjelasan di atas terlihat bahwa penjualan terutama penjualan Indihome unit bisnis simpang limun mengalami penurunan pada bulan Februari, Mei dan Juni yang cukup signifikan, hal itu tentu dapat membuat perusahaan jasa penyediaan layanan informasi dan telekomunikasi berlomba lomba menyediakan jasa layanan informasi dan telekomunikasi dengan berbagai fasilitas terbaik untuk menarik perhatian masyarakat Indonesia, di Indonesia Banyak Perusahaan Jasa Penyedia Layanan Internet di Indonesia.

Tabel 1

Daftar Perusahaan penyedia

Jasa Internet di Indonesia

\begin{tabular}{llll}
\hline No & \multicolumn{1}{c}{ Nama Perusahaan } & No & \multicolumn{1}{c}{ Nama Perusahaan } \\
\hline 1 & RADNET, Jakarta & 35 & PT Terminal Adi Persada \\
\hline 2 & PT. Cyberindo Aditama & 36 & PT. Jasnita Telekomindo \\
\hline 3 & Pacific Link & 37 & $\begin{array}{l}\text { Jaringan Komunikasi } \\
\text { danInformasi }\end{array}$ \\
\hline 4 & PT. Carakayasa Binekatara & 38 & Konsorsium PJI Indonesia \\
\hline 5 & PT. Transmedia Mitra Internet & 39 & PT. Bima Putera Utama \\
\hline 6 & PT. Millenium Internetindo & 40 & $\begin{array}{l}\text { Seruling Indah Permai } \\
\text { (LinkNet) }\end{array}$ \\
\hline 7 & PT. Internet Madju Abad Millenindo & 41 & P.T. Pilar Pradana Intimedia \\
\hline 8 & PT. Alpha Netindo Pratama & 42 & MEGA.NET.ID - ISP - \\
\hline
\end{tabular}




\begin{tabular}{|c|c|c|c|}
\hline No & Nama Perusahaan & No & Nama Perusahaan \\
\hline & & & JAKARTA \\
\hline 9 & Asia Pacific Internet Company & 43 & P.T. Melvar Lintasnusa \\
\hline 10 & ASIA.NET.ID - ISP - INDONESIA & 44 & P.T. Multimedia Nusantara \\
\hline 11 & PT. Parikesit Perwira & 45 & PT Metrodata Electronics Tbk \\
\hline 12 & PT. Bitnet Komunikasindo & 46 & P.T. Surya Mitra Internet \\
\hline 13 & Pt Bumisejahtera Intikencana & 47 & PT. Kartika Telesys \\
\hline 14 & Centrin Internet & 48 & $\begin{array}{l}\text { PT. GLOBALINTER } \\
\text { NETURA }\end{array}$ \\
\hline 15 & $\begin{array}{l}\text { PT. Total Info Kharisma (Central } \\
\text { Online) }\end{array}$ & 49 & P.T. Jasa Jejaring Wasantara \\
\hline 16 & $\begin{array}{l}\text { PT Gema Nusa Perkasa / } \\
\text { KOPPOSTEL } \\
\text { DITJEN POSTEL }\end{array}$ & 50 & PT. Pasifik Satelit Nusantara \\
\hline 17 & P.T. Inasha Yudhabakti & 51 & P.T. Khasanah Timur Indonesia \\
\hline 18 & PT. Datamation Purwana Utama & 52 & $\begin{array}{l}\text { PT. PRIMEDIA } \\
\text { ARMOEKADATA }\end{array}$ \\
\hline 19 & Wireless-Mobile Internet service & 53 & PT. Pasifik Satelit Nusantara \\
\hline 20 & PT Dyviacom Intrabumi & 54 & PT.Satata Neka Tama \\
\hline 21 & PT. Elga Yasa Media & 55 & SigNet \\
\hline 22 & PT Telesindo Media Utama & 56 & $\begin{array}{l}\text { PT TELEKOMUNIKASI } \\
\text { INDONESIA, tbk }\end{array}$ \\
\hline 23 & PT. Infotek mitrasejati & 57 & P.T. Sistelindo Mitralintas \\
\hline 24 & Widya Caraka Putra Pertiwi, PT. & 58 & PT. Usaha Mediantara Intranet \\
\hline 25 & PT EXCELCOMINDO PRATAMA & 59 & $\begin{array}{l}\text { PT Starkomindo } \\
\text { DutaInfoCemerlang }\end{array}$ \\
\hline & IBM Global Network Indonesia & 60 & PT Telesindo Mulia \\
\hline & PT. Aplikanusa Lintasarta & 61 & $\begin{array}{l}\text { PT Telekomunikasi } \\
\text { Indonesia, tbk }\end{array}$ \\
\hline & APJII - IIX & 62 & PT. Uninet Bhaktinusa \\
\hline & PT. IndoInternet, Indonesia & 63 & Uninet Media Sakti \\
\hline & PT INDOSAT / INDOSATnet & 64 & $\begin{array}{l}\text { P.T. Visionindo Network } \\
\text { Perdana }\end{array}$ \\
\hline & PT. Indosoftindo Ciptapiranti & 65 & PT. Pos Indonesia \\
\hline 32 & P.T. Sejahtera Globalindo & 66 & Wireless Data Access \\
\hline & P.T. Ramaduta Teltaka & 67 & BKS PTN INTIM \\
\hline
\end{tabular}

Sumber: http://www.bijt.org/scriptie/scriptie/Scriptie/links/ListISP_bestanden/ISP.htm

PT. Telkom Indonesia (Persero) Tbk. merupakan salah satu perusahaan yang bergerak pada jasa telekomunikasi. Pemenuhan akan kebutuhan teknologi internet di Masyarakat di jawab dengan dikembangkannya produk berbasis pemenuhan kebutuhan atas akses internet, salah satu produknya adalah speedy yang telah berubah seiring perkembangan teknologi menjadi Indihome (Indonesia digital home). Hal inilah yang membuat PT. Telkom Indonesia (Persero) Tbk. berusaha mengembangkan dan memberikan yang terbaik dilingkungan masyarakat agar nilai jual dan penguna jasa 
perusahaan PT. Telkom Indonesia (Persero) Tbk. mampu bersaing dengan penyedia jasa internet lain nya, terkhusus nya dikota Medan. Diharapkan Indihome mampu memberikan Kontribusi yang baik.

Saat ini formal promosi yang digunakan dalam mempromosikan produk IndiHome terdiri dari 3 saluran yaitu penjualan pribadi (Personal Selling), periklanan (Advertising), dan promosi penjualan (Sales Promotion). Tabel 2 merupakan detail promosi yang digunakan dalam mempromosikan produk IndiHome: Setelah dilakukan identifikasi saluran promosi yang digunakan untuk mempromosikan produk IndiHome.

Tabel 2

Promotion Mix IndiHome

\begin{tabular}{rlc}
\hline No. & Saluran Promotion Mix & Persentasi \\
\hline 1. & Periklanan (Advertising) & $15 \%$ \\
\hline 2. & $\begin{array}{l}\text { Penjualan Pribadi (Personal } \\
\text { Selling) }\end{array}$ & $65 \%$ \\
\hline 3. & $\begin{array}{l}\text { Promosi Penjualan (Sales } \\
\text { Promotion) }\end{array}$ & $20 \%$ \\
\hline
\end{tabular}

Tersedianya promosi yang beraneka ragam bukan berarti terbuka kesempatan bagi perusahaan untuk begitu saja memilih tanpa pertimbangan yang matang. Semakin beraneka ragam media promosi yang dipakai, justru semakin banyak faktor yang harus dipertimbangkan perusahaan sebelum melakukan kegiatan promosi. Faktor yang perlu dijadikan bahan pertimbangan dalam memilih media promosi antara lain : keadaan persaingan pasar, sifat produk yang ditawarkan, siklus kehidupan produk dan anggaran biaya promosi yang tersedia.

Peranan PT. Telkom Indonesia (Persero) Tbk. mencari konsumen agar Mengunakan Jasa Internet yang mereka sediakan merupakan tugas pokok dari perusahaan dimana berbagai strategi digunakan untuk memasarkan produk agar sampai kemasyarakat salah satunya adalah Personal Selling, Strategi pemasaran ini diharapkan mampu mendongkrak perkembangan penjualan produk yang disajikan oleh PT. Telkom Indonesia (Persero) Tbk.

Personal selling mempunyai peranan penting dalam mempromosikan produk, dan Jasa agar produk dan jasa Yang disajikan oleh perusahaan sampai ketangan konsumen. Masalahnya adalah ada beberapa personal selling yang menjual produk di bawah target yang perusahaan berikan kepada semua personal selling indihome. Hal inilah yang membuat peneliti tertarik meneliti "Pengaruh Personal Selling Terhadap Pencapaian Target Penjualan (PT. Telkom Indonesia (Persero) Tbk. Unit Bisnis Simpang Limun Medan)".

\section{Metode Penelitian}

Desain penelitian merupakan rancangan penelitian yang digunakan sebagai pedoman dalam melakukan proses penelitian, Desain penelitian adalah: kerangka atau perincian prosedur kerja yang akan dilakukan pada waktu meneliti, sehingga diharapkan 
dapat memberikan gambaran dan arah mana yang akan dilakukan dalam melaksanakan penetian tersebut, serta memberikan gambaran jika peneletian itu telah jadi atau selesai penelitian tersebut diberlakukan.

Populasi merupakan wilayah generalisis yang terdiri dari objek yang memiliki kualitas yang memiliki nilai dan hasil perhitungan yang lengkap dan jelas. Marketing PT. Telkom Indonesia (Persero) Tbk. Unit Bisnis Simpang Limun Medan dengan jumlah 50 orang. Menurut Sugiyono, Sampel adalah bagian dari jumlah dan karakteristik yang dimiliki oleh populasi tersebut. Adapun teknik sampling dalam penelitian ini digunakan yaitu probability sampling. Menurut Sugiyono bahwa: Probability sampling adalah teknik pengambilan sampel yang memberikan peluang yang sama bagi setiap unsur (anggota) populasi untuk dipilih menjadi sampel. Maka yang menjadi sampel dalam penelitian ini adalah seluruh total populasi Marketing PT. Telkom Indonesia (Persero) Tbk. Unit Bisnis Simpang Limun Medan sebanyak 50 orang.

\section{Hasil dan Pembahasan}

Uji validitas digunakan untuk mengukur sah atau valid tidaknya suatu kuesioner. Sebuah instrumen atau kuesioner dikatakan valid jika pertanyaan pada instrumen atau kuesioner mampu mengungkapkan sesuatu yang akan diukur oleh kuesioner tersebut (Ghozali, 2018). Uji Validitas dilakukan untuk mengukur apakah data yang telah didapat setelah penelitian yang merupakan data yang valid dengan alat ukur yang digunakan dalam meneliti, yaitu kuesioner. Uji validitas terlebih dahulu dilakukan dengan menyebar kuesioner kepada 30 responden diluar responden penelitian ini yaitu PT. Telkom Indonesia (Persero) Tbk. Unit Bisnis Simpang Limun

1. Jika rhitung $>$ rtabel maka dinyatakan valid.

2. Jika rhitung < rtabel maka dinyatakan tidak valid.

Diketahui bahwa rtabel menggunakan taraf signifikan $\mathrm{n}=10$ responden sehingga diperoleh $(\mathrm{df}=\mathrm{n}-2)$, dengan taraf signifikansi 5\% atau sama dengan 0,05 sehingga rtabel yang didapatkan yaitu sebesar $=0,30$ (Dahlan, 2004).

Tabel 1

Hasil Uji Validitas Personal Selling (X)

\begin{tabular}{|c|c|c|c|c|}
\hline \multirow[b]{3}{*}{ No } & \\
\hline & & & \multirow[b]{2}{*}{ rtabel } & \multirow[b]{2}{*}{ Validitas } \\
\hline & Pernyataan & $\begin{array}{l}\text { Corrected } \\
\text { Item Total } \\
\text { Correlation } \\
\text { (rhitung) }\end{array}$ & & \\
\hline 1. & $\begin{array}{lrrr}\text { Sebagai Tenaga } & \text { penjual } & \text { Indihome } & \text { harus } \\
\text { berpenampilan rapi } & & & \end{array}$ & 0,910 & 0,361 & Valid \\
\hline 2. & $\begin{array}{l}\text { Sebagai Tenaga penjual harus mengenalkan } \\
\text { identitas diri sebelum menawarkan produk }\end{array}$ & 0,868 & 0,361 & Valid \\
\hline 3. & $\begin{array}{l}\text { Sebagai Tenaga penjual harus bersikap ramah } \\
\text { ketika menyapa calon konsumen }\end{array}$ & 0,685 & 0,361 & Valid \\
\hline 4. & $\begin{array}{l}\text { Sebagai marketing indihome kamu menggunakan } \\
\text { bahasa yang mudah dimengerti pelangggan }\end{array}$ & 0,593 & 0,361 & Valid \\
\hline
\end{tabular}




\begin{tabular}{clccc}
\hline No & \multicolumn{1}{c}{ Pernyataan } & \multicolumn{1}{c}{$\begin{array}{c}\text { Corrected } \\
\text { Item } \begin{array}{c}\text { Total } \\
\text { Correlation } \\
\text { (rhitung) }\end{array}\end{array}$} & rtabel & Validitas \\
\hline 5. & $\begin{array}{l}\text { Sebagai Tenaga penjual kamu mau menjawab } \\
\text { keberatan yang dirasakan konsumen }\end{array}$ & 0,828 & 0,361 & Valid \\
\hline $6 . \quad \begin{array}{l}\text { Sebagai Tenaga penjual kamu harus bersikap } \\
\text { ramah ketika menanggapi keberatan konsumen }\end{array}$ & 0,853 & 0,361 & Valid \\
\hline $7 . \quad \begin{array}{l}\text { Sebagai Tenaga penjual kamu harus bersikap baik } \\
\text { kepada konsumen lama dan baru }\end{array}$ & 0,795 & 0,361 & Valid \\
\hline $8 . \quad \begin{array}{l}\text { Tenaga penjual ada catatan tentang konsumen } \\
\text { lama }\end{array}$ & 0,853 & 0,361 & Valid \\
\hline 9. & $\begin{array}{l}\text { Sebagai Tenaga penjual kamu harus menjelaskan } \\
\text { secara rinci mengenai keunggulan produknya }\end{array}$ & 0,857 & 0,361 & Valid \\
\hline $10 . \quad \begin{array}{l}\text { Sebagai Tenaga penjual kamu harus menguasai } \\
\text { pengetahuan tentang produknya }\end{array}$ & 0,550 & 0,361 & Valid \\
\hline
\end{tabular}

Setelah dilakukan pengujian Validitas data Variabel Personal Selling (X1) yang terlihat pada tabel 4.23 dengan $\mathrm{df}=\mathrm{n}-2$ yaitu $\mathrm{df}=30-2=28$ dan $\alpha=0,05$ seluruh pernyataan adalah Valid yaitu nilai corrected Item Total correlation seluruhnya bernilai lebih besar dari 0,361 .

\section{Tabel 2}

Hasil Uji Validitas Target Penjualan

\begin{tabular}{clccc}
\hline \multicolumn{1}{c}{ Pernyataan } & \multicolumn{1}{c}{$\begin{array}{c}\text { Corrected Item } \\
\text { Total } \\
\text { Correlation } \\
\text { (rhitung) }\end{array}$} & rtabel & Validitas \\
\hline 1 & $\begin{array}{l}\text { Tenaga penjual indihome melakukan promosi di berbagai } \\
\text { media sosial seperti : facebook, } \\
\text { twiter, ig dll. }\end{array}$ & 0,624 & 0,361 & Valid \\
\hline 2 & $\begin{array}{l}\text { Tenaga penjual melakukan promosi dijalan dengan cara } \\
\text { membuka stand dan membagikan } \\
\text { brosur dijalan }\end{array}$ & 0,800 & 0,361 & Valid \\
\hline 3 & $\begin{array}{l}\text { Tenaga penjual melakukan promosi kepada } \\
\text { orang terdekat }\end{array}$ & 0,699 & 0,361 & Valid \\
\hline 4 & $\begin{array}{l}\text { Marketing melakukan berbagai cara untuk } \\
\text { melakukan promosi }\end{array}$ & 0,637 & 0,361 & Valid \\
\hline 5 & $\begin{array}{l}\text { Tenaga penjual indihome } \\
\text { informasi tentang kualitas produk }\end{array}$ & 0,747 & 0,361 & Valid \\
\hline 6 & $\begin{array}{l}\text { Tenaga penjual mengetahui semua informasi } \\
\text { tentang indihome }\end{array}$ & 0,798 & 0,361 & Valid \\
\hline 7 & $\begin{array}{l}\text { Tenaga penjual mengetahui tentang promo } \\
\text { indihome }\end{array}$ & 0,808 & 0,361 & Valid \\
\hline 8 & $\begin{array}{l}\text { Tenaga penjual indihome melakukan pelayanan } \\
\text { yang sangat baik dan ramah }\end{array}$ & 0,763 & 0,361 & Valid \\
\hline 9 & $\begin{array}{l}\text { Marketing melayani konsumen dengan sabar } \\
\text { Marketing melayani konsumen dengan keluhan }\end{array}$ & 0,781 & 0,361 & Valid \\
\hline 10 & yang banyak dan marah - marah & 0,683 & 0,361 & Valid \\
\hline
\end{tabular}

Sumber: Data diolah oleh Peneliti, 2021 
Setelah dilakukan pengujian Validitas data Variabel Target Penjualan (Y1) yang terlihat pada tabel 4.24 dengan $\mathrm{df}=\mathrm{n}-2$ yaitu $\mathrm{df}=30-2=28$ dan $\alpha=0,05$ seluruh pernyataan adalah Valid yaitu nilai corrected Item Total correlation seluruhnya bernilai lebih besar dari 0,36

Tabel 3

Hasil Uji Reliabilitas instrument Variabel Personal Selling Reliability Statistics

\begin{tabular}{cc}
\hline Cronbach's Alpha N of Items \\
\hline, 926 & 10 \\
\hline Sumber: Data diolah oleh Peneliti, 2021 &
\end{tabular}

Dari tabel diatas menunjukan bahwa instrumen penelitian pada penelitian ini telah memenuhi unsur reliabilitas yang baik, dengan kata lain instrumen penelitian ini adalah reliabel atau terpercaya, tingkat instrumen penelitian sudah memadai karena Cronbach' Alpha > 0,926 $(0,926>0,05)$. Dari

\begin{tabular}{cc}
\hline Cronbach's Alpha & N of Items \\
\hline, 904 & 10 \\
\hline
\end{tabular}

Sumber: Data diolah oleh Peneliti ,2021

Dari tabel 4 menunjukan bahwa instrumen penelitian pada penelitian ini telah memenuhi unsur reliabilitas yang baik, dengan kata lain instrumen penelitian ini adalah reliabel atau terpercaya, tingkat instrumen penelitian sudah memadai karena Cronbach' Alpha > 0,926 $(0,926>0,05)$. Dari hasil analisis data item-item tersebut dapat dinyatakan reliabel apabila Cronbach' Alpha $>0,05$. Dari 10 angket yang di ujicobakan dinyatakan semua butir item angket dinyatakan reliabel atau konsisten.

Tabel 5

Hasil Uji Reliabilitas instrument Variabel Pencapaian Target Reliability Statistics

\begin{tabular}{rr}
\hline Cronbach's Alpha & N of Items \\
\hline 904 & 10 \\
\hline
\end{tabular}

Sumber: Data diolah oleh Peneliti, 2021

Dari tabel 5 menunjukan bahwa instrumen penelitian pada penelitian ini telah memenuhi unsur reliabilitas yang baik, dengan kata lain instrumen penelitian ini adalah reliabel atau terpercaya, tingkat instrumen penelitian sudah memadai karena Cronbach' Alpha > 0,904 (0,904>0,05). Dari hasil analisis data item-item tersebut dapat dinyatakan reliabel apabila Cronbach' Alpha $>0,05$. Dari 10 angket yang di ujicobakan dinyatakan semua butir item angket dinyatakan reliabel atau konsisten. 
Pengaruh Personal Selling terhadap Pencapaian Target Penjualan (Studi Kasus PT.

Telkom Indonesia (Persero) Tbk

Tabel 5

Uji Normalitas

One-Sample Kolmogorov-Smirnov Test Unstandardized Residual

\begin{tabular}{llr}
\hline $\mathrm{N}$ & & 50 \\
\hline Normal Parameters & Mean &, 0000000 \\
\hline & Std. Deviation & 2,66312956 \\
\hline Most Extreme Differences & Absolute &, 060 \\
\hline & Positive &, 044 \\
\hline & Negative &,- 060 \\
\hline Test Statistic & &, 060 \\
\hline Asymp. Sig. (2-tailed) & &, $200^{\mathrm{c}, \mathrm{d}}$ \\
\hline
\end{tabular}
a. Distribution is Normal.
b. Calculated from data.
c. Lilliefors Significance Correction.
$\mathrm{d}$. This is a lower bound of the true significance.

Hasil Kolmogrov-Smirnov menunjukkan angka 0,200 dengan tingkat signifikansi yang berarti berada diatas 0.05 dengan demikian dapat disimpulkan bahwa variable telah terdistribusi secara normal.

Tabel 6

Analisis Regresi Linear Seserhana Model Summary ${ }^{b}$

\begin{tabular}{|c|c|c|c|c|}
\hline Model & $\mathbf{R}$ & R Square & $\begin{array}{l}\text { Adjusted } \\
\mathbf{R} \\
\text { Square } \\
\end{array}$ & $\begin{array}{l}\text { Std. Error of } \\
\text { the } \\
\text { Estimate }\end{array}$ \\
\hline 1 &, $746^{\mathrm{a}}$ &, 557 &, 547 & 2,691 \\
\hline
\end{tabular}

Berdasarkan tabel output SPSS di atas, diketahui nilai koefisien determinasi atau $\mathrm{R}$ square adalah sebesar 0,557 . Nilai $\mathrm{R}$ square ini berasal dari pengkuadratan nilai koefisien korelasi atau $\mathrm{R}$ yaitu $746 \times 746=0,746$. Besarnya angka koefisien determinasi $\mathrm{R}$ square adalah 0,557 atau sama dengan 55,7\%. Angka tersebut mengandung arti bahwa variabel Personal Selling berpengaruh signifikan dan simultan terhadap Peningkatan Target Penjualan Pada PT. Telkom Indonesia (Persero) Tbk. Unit Bisnis Simpang Limun Medan sebesar 55,7\%. 
Tabel 7

Uji t (Parsial)

Coefficients $^{\mathbf{a}}$

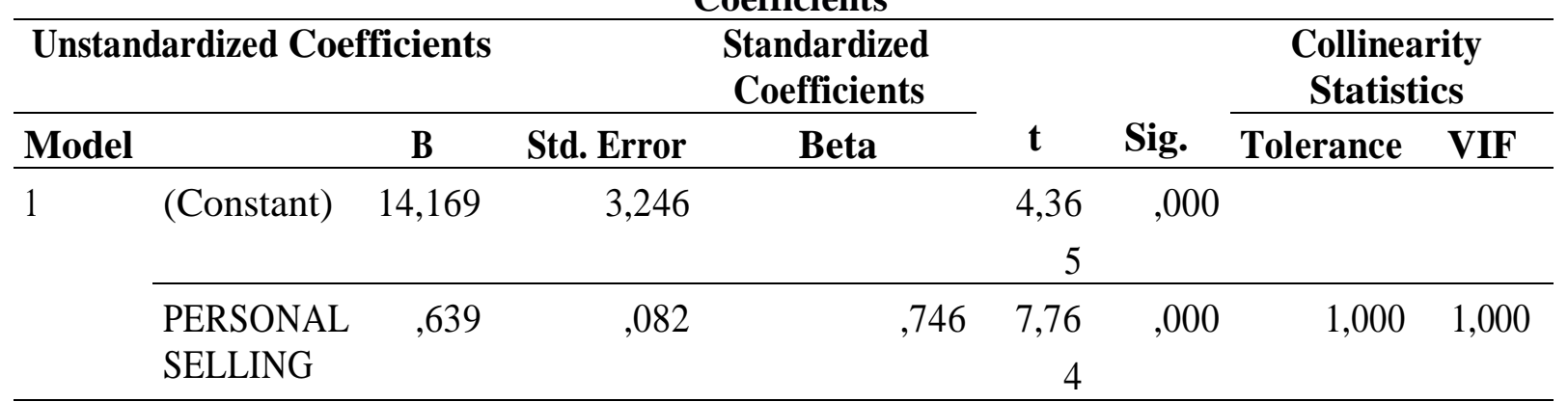

a. Dependent Variable: Pencapaian Target Penjualan

Sumber: Data diolah oleh Peneliti , 2021

Berdasarakan tabel diatas, diperoleh nilai thitung sebesar 7,764 dengan tingkat signifikan 0,000. Sedangkan nilai ttab sebesar 0,847. Karena t hitung $(7,764)>t$ tab $(0,361)$ artinya Personal Selling berpengaruh signifikan terhadap Peningkatan Target Penjualan Pada PT. Telkom Indonesia (Persero) Tbk Unit Bisnis Simpang Limun Medan.

Uji t dilakukan untuk mengetahui pengaruh variabel independen yaitu Personal Selling terhadap Target Penjualan. Kriteria penerimaan/penolakan hipotesis adalah sebagai berikut:

1) Bila Sig > 0,05 dan thitung < ttabel, maka $\mathrm{H} 0=$ diterima, sehingga tidak ada pengaruh signifikan antara variabel bebas dan terkait.

2) Bila Sig $<0,05$ dan thitung $>$ ttabel, maka $\mathrm{HO}=$ ditolak, sehingga ada pengaruh signifikan antara variabel bebas dan terikat.

3) Koefisian determinasi terletak pada tabel Model Summary dan tertulis R Square. Untuk regresi linier sederhana sebaiknya menggunakan R Square yang sudah disesuaikan atau tertulis Adjusted R Square karena disesuaikan dengan jumlah variabel yang digunakan dalam penelitian nilai $\mathrm{R}$ Square/Adjusted $\mathrm{R}$ Square dikatakan baik jika diatas 0,5 karena nilai R Square berkisar 0 sampai dengan 1 . Hasil analisis koefisien determinasi dalam penelitian ini adalah:

Tabel 8 Uji

Determinasi $\left(\mathbf{R}^{2}\right)$

Model Summary ${ }^{b}$

\begin{tabular}{|c|c|c|c|c|}
\hline Model & $\mathbf{R}$ & R Square & $\begin{array}{c}\text { Adjusted R } \\
\text { Square }\end{array}$ & $\begin{array}{l}\text { Std. Error of } \\
\text { the } \\
\text { Estimate }\end{array}$ \\
\hline 1 &, $746^{\mathrm{a}}$ & ,557, & ,547 & 2,691 \\
\hline
\end{tabular}

Sumber: Data diolah oleh Peneliti, 2021 
Berdasarkan tabel output SPSS di atas, diketahui nilai koefisien determinasi atau $\mathrm{R}$ square adalah sebesar 0,557 . Nilai $\mathrm{R}$ square ini berasal dari pengkuadratan nilai koefisien korelasi atau $\mathrm{R}$ yaitu $746 \times 746=0,746$. Besarnya angka koefisien determinasi $\mathrm{R}$ square adalah 0,557 atau sama dengan 55,7\%. Angka tersebut mengandung arti bahwa variabel Personal Selling berpengaruh signifikan dan simultan terhadap Peningkatan Target Penjualan Pada PT. Telkom Indonesia (Persero) Tbk. Unit Bisnis Simpang Limun Medan sebesar 55,7\%.

\section{Kesimpulan}

Berdasarkan hasil pengolahan data dan analisis yang telah dilakukan, terdapat 3 kesimpulan yang menjawab tujuan dari penelitian pengaruh personal selling terhadap pencapaian target penjualan (studi kasus PT. Telkom indonesia (persero) tbk. Unit bisnis simpang limun medan), berdasarkan hasil yang diperoleh thitung $>$ ttabel (7,764 > 0,361) maka dapat disimpulkan bahwa HO ditolak dan H1 diterima, yaitu artinya ada Pengaruh postif dan signifikan antarta Personal Selling Terhadap Target Penjualan.

Nilai koefisien determinasi atau $\mathrm{R}$ square adalah sebesar 0,557 . Nilai $\mathrm{R}$ square ini berasal dari pengkuadratan nilai koefisien korelasi atau $\mathrm{R}$ yaitu $746 \times 746=0,746$. Besarnya angka koefisien determinasi $\mathrm{R}$ square adalah 0,557 atau sama dengan 55,7\%. Angka tersebut mengandung arti bahwa variabel Personal Selling berpengaruh signifikan dan simultan terhadap Peningkatan Target Penjualan Pada PT. Telkom Indonesia (Persero) Tbk. Unit Bisnis Simpang Limun Medan sebesar 55,7\%. 


\section{BIBLIOGRAFI}

Devika, Mutiara. 2015. "Analisis Pengaruh Promotion Mix Produk Indihome PT. Telekomunikasi Indonesia Tbk. Regional V Jawa Timur Terhadap Keputusan Pembelian." http://repository.its.ac.id/70993/.Google Scholar

Handayani, Sri. 2017. "Pengaruh Penyelesaian Klaim Asuransi Terhadap Pencapaian Target Penjualan Produk Asuransi Ajb Bumiputera 1912 Cabang Bengkulu." Ekombis Review: Jurnal Ilmiah Ekonomi dan Bisnis 5(1): 79-85. Google Scholar

Kotler , P dan Garry Armstrong. (2012).Perinsip-Perinsip Pemasaran. Edisi 13 Jilid 1. Jakarta : Erlangga. Google Scholar

Kotler, P. \& Keller, K.L. (2012), Manajemen Pemasaran. Jilid I dan II Edisi ke 13. Jakarta: Erlangga. Google Scholar

Kusmayani, yunita.( 2014), Pengaruh Personal Selling Terhadap Keputusan Pembelian Produk Oriflame Di Queneno Group Singaraja Tahun 2014. Jurnal Ekonomi Pendidikan Undiksha. Vol :4 Nomor 1 tahun 2014. Google Scholar

Muchina, Caroline Muthoni, and Barrack Okello. 2016. "Influence of Personal Selling on Brand Performance of Retail Shoe Companies in Nairobi Central Business District." International Journal of Academic Research in Business and Social Sciences 6(5): 1-14. Google Scholar

Natalia Elisabeth. (2018), Pengaruh Merek Dan Personal Selling Terhadap Keputusan Pembelian Produk Dvd Player Elecor Pada Pt. Cakrawala Elecorindo Medan. PIssn : 2301-7775 E-Issn : 2579-8014 Niagawan Vol 7 No 2 Juli 2018. Google Scholar

Nurmartiani, Erica Sucherly Meydia Hasan Rita Komaladewi. 2019. "Customer Value in Improving Indihome Customer' S Trust in West Java." Academy of Marketing Studies Journal 23(4): 2011-12. Google Scholar

Prasetyo, Adhitya Aji, and Oce Ridwanudin. 2017. "Pengaruh Personal Selling Terhadap Keputusan Berkunjung Di Jendela Alam." THE Journal : Tourism and Hospitality Essentials Journal 6(2): 1077. Google Scholar

Putra ,Medyana (2016). Analisis Faktor-Faktor Yang Mempengaruhi Volume Penjualan Pada Ud. Wayan Fiber Glass Singaraja Tahun 2014 e-Journal Bisma Universitas Pendidikan Ganesha Jurusan Manajemen (Volume 4 Tahun 2016). Google Scholar

Saragih, Hendri. 2017. Analisis Faktor Pendorong Pemasaran Ekspor Dan Pengaruhnya Terhadap Peningkatan Volume Penjualan Pada Pt. Perkebunan Nusantara II (Persero) Medan Jurnal Ilmiah Methonomi Vol. 3 No. 2 (Juli Desember 2017). Google Scholar 
Siregar, Ina Namora Putri, and Elisabeth Natalia. 2018. "Pengaruh Merek Dan Personal Selling Terhadap Keputusan Pembelian Produk Dvd Player Elecor Pada Pt. Cakrawala Elecorindo Medan.” Niagawan 7(2): 80-89. Google Scholar

Sugiyono, (2017). Statistika Untuk Penelitian: CV Alfabeta Bandung.

Sugiyono, (2014). Metode Penelitian Pendidikan Pendekatan Kuantitatif, Kualitatif, dan R\&D. Bandung: Alfabeta. Google Scholar

Suryana. 2013. Ekonomi Keatif, Ekonomi Baru: Mengubah Ide dan Menciptakan Peluang. Jakarta: Salemba Empat. Google Scholar

Tumbelaka, Michael, and Loindong Sjendry. 2014. "Servicescape Dan Personal Selling Pengaruhnya Terhadap Kepuasan Nasabah Tabungan Britama Bank Bri Cabang Manado." Jurnal Riset Ekonomi, Manajemen, Bisnis dan Akuntansi 2(2): 1239-50. Google Scholar

Winardi. 2011. Motivasi Pemotivasian. Jakarta: PT. Raja Grafindo Persada.

Yudhiartika, Dian, and Jony Haryanto. 2012. "Pengaruh Personal Selling, Display, Promosi Penjualan Terhadap Kesadaran Merek Dan Intensi Membeli Pada Produk Kecantikan Pondâ $€^{\mathrm{TM}}$ S.” Buletin Studi Ekonomi 17(2): 142-56. Google Scholar

\section{Copyright holder:}

Mahyani, Sari Wulandari (2021)

First publication right:

Syntax Idea

This article is licensed under: 